\title{
ZNF280BY and ZNF280AY: autosome derived Y-chromosome gene families in Bovidae
}

\author{
Yang Yang ${ }^{1,5 \dagger}$, Ti-Cheng Chang ${ }^{1,2 \dagger}$, Hiroshi Yasue ${ }^{3}$, Arvind K Bharti ${ }^{4}$, Ernest F Retzel ${ }^{4}$, Wan-Sheng Liu ${ }^{1,2^{*}}$
}

\begin{abstract}
Background: Recent progress in exploring the Y-chromosome gene content in humans, mice and cats have suggested that "autosome-to-Y" transposition of the male fertility genes is a recurrent theme during the mammalian Y-chromosome evolution. These transpositions are lineage-dependent. The purpose of this study is to investigate the lineage-specific Y-chromosome genes in bovid.

Results: We took a direct testis CDNA selection strategy and discovered two novel gene families, ZNF280BY and ZNF280AY, on the bovine (Bos taurus) Y-chromosome (BTAY), which originated from the transposition of a gene block on the bovine chromosome 17 (BTA17) and subsequently amplified. Approximately 130 active ZNF280BY loci (and $\sim 240$ pseudogenes) and 130 pseudogenized ZNF280AY copies are present over the majority of the malespecific region (MSY). Phylogenetic analysis indicated that both gene families fit with the "birth-and-death" model of evolution. The active ZNF280BY loci share high sequence similarity and comprise three major genomic structures, resulted from insertions/deletions (indels). Assembly of a 1.2 Mb BTAY sequence in the MSY ampliconic region demonstrated that ZNF280BY and ZNF280AY, together with HSFY and TSPY families, constitute the major elements within the repeat units. The ZNF280BY gene family was found to express in different developmental stages of testis with sense RNA detected in all cell types of the seminiferous tubules while the antisense RNA detected only in the spermatids. Deep sequencing of the selected CDNAs revealed that different loci of ZNF280BY were differentially expressed up to 60-fold. Interestingly, different copies of the ZNF280AY pseudogenes were also found to differentially express up to 10-fold. However, expression level of the ZNF280AY pseudogenes was almost 6-fold lower than that of the ZNF280BY genes. ZNF280BY and ZNF280AY gene families are present in bovid, but absent in other mammalian lineages.
\end{abstract}

Conclusions: ZNF280BY and ZNF280AY are lineage-specific, multi-copy Y-gene families specific to Bovidae, and are derived from the transposition of an autosomal gene block. The temporal and spatial expression patterns of ZNF280BYs in testis suggest a role in spermatogenesis. This study offers insights into the genomic organization of the bovine MSY and gene regulation in spermatogenesis, and provides a model for studying evolution of multi-copy gene families in mammals.

\section{Background}

Sex-determination in Eutheria depends on the $\mathrm{X}$ and $\mathrm{Y}$ chromosomes (X/Y-chr) that evolved from a pair of autosomes less than 166 million years ago (Mya), after the divergence of the monotreme lineage [1,2]. Acquisition of a sex-determining locus $(S R Y)$ transformed the ancestral autosomes to the proto-X/Y [3] and a subsequent stepwise

\footnotetext{
* Correspondence: wul12@psu.edu

+ Contributed equally

'Department of Dairy and Animal Science, The Center for Reproductive Biology and Health (CRBH), College of Agricultural Sciences, The

Pennsylvania State University, University Park, PA 16802, USA

Full list of author information is available at the end of the article
}

suppression of meiotic recombination between $\mathrm{X}$ and $\mathrm{Y}$ led to a male-specific region on the Y-chr (MSY) [3,4]. The remaining euchromatic region of the Y-chr, the pseudoautosomal region (PAR), retains the ability to recombine with the X-chr during meiosis and shares the same genes and DNA sequences with its $X$ counterpart [3,5-9]. The Y-chr, compared to the gene-rich ( 1600 genes) and highly conserved X-chr, has degenerated and lost more than $95 \%$ of ancestral genes, and is poorly conserved among mammalian lineages [7,9-11]. After recombination was suppressed with the X-chr, degeneration of the Y-chr was driven by several synergistic evolutionary forces, 
including Muller's ratchet, background selection, the Hill Robertson effect with weak selection and hitchhiking of deleterious alleles by favorable mutations $[12,13]$. Independent Y-chr decay during evolution [3,14] led to different eutherian lineages retaining different subsets of $Y$ genes, and a diverse and lineage-specific $\mathrm{Y}$-chr gene content.

Male-benefit genes have accumulated on the Y-chr through persistence of genes derived from the proto-X/ $Y$ [3], transposition and retroposition from autosomes and subsequent amplification [15-18]. Y-chr gene amplification with an attendant higher level of expression has been suggested to enhance gene function particularly beneficial to the male $[4,19]$. As a result, gene accumulation and amplification have provided the Y-chr with a functional coherence in sex determination, spermatogenesis and fertility not observed in other regions of eutherian genomes [15], with genes in MSY showing remarkably uniform expression patterns either exclusively or predominantly in the testis $[4,19]$.

To date, several lineage-specific Y-chr gene families, including the human $D A Z, C D Y$, the mouse Ssty1 and the cat TETY1 and FLJ36031, have been reported [4,18,20-22]. DAZ and $C D Y$ appear as main candidates for the human Azoospermia Factor (AZF) [23-32]. Although these two primate lineage-specific $Y$ genes are autosomal in cattle and other non-primates, their functions in spermatogenesis and male fertility are highly conserved in the non-primate autosomal orthologs [4,24,32-34].

Causal reasons for the species-specific accumulation of Y-genes remain elusive, as little information is available regarding the gene content of the Y-chr in most eutherian mammals. We believed that the identification of species-specific Y-genes in individual species will increase our understanding of the mechanisms underlying gene acquisition and evolution, and offer insights into the genes central to regulation of male fertility and spermatogenesis.

The bovine (Bos taurus) Y-chr (BTAY) was estimated to be $\sim 1.77 \%(\sim 51 \mathrm{Mb})$ of the entire bovine genome $(2.87 \mathrm{~Gb})[35,36]$. The MSY region comprises $\sim 95 \%$ of BTAY, approximately $50 \%$ of which belongs to the euchromatic region ( 24 Mb) [37]. Previous studies on BTAY were based on a comparative mapping approach [37], resulting in several Y-linked genes, such as AMELY, DDX3Y, SRY, TSPY, UTY and ZFY [38-41]. However, due to the limitation of the comparative mapping approach, lineage-specific $\mathrm{Y}$-chr gene(s) has not been extensively analyzed in bovid.

The purpose of the present study is to investigate the MSY region, and to identify and characterize the bovid lineage-specific $\mathrm{Y}$-chr gene(s). By using a direct testis cDNA selection approach $[20,42]$, we discovered two bovine-specific Y-chr gene families-ZNF280BY (Zinc finger protein $280 B$ Y-link, also known as SUHW2, suppressor of hairy wing homolog 2) and ZNF280AY (Zinc finger protein $280 A$ Y-link, or SUHW1), which originated from a segmental duplication of their paralogs on the bovine chr 17 (BTA17) and were subsequently amplified to over 100 copies on BTAY. To our knowledge, this is the first report on an autosome-to-Y "gene block" transposition. The transposition and amplification of ZNF280B/ZNF280A on the bovid $Y$-chr provides a fundamental model for further studying the expansion of multigene families on Y-chr and for understanding the evolutionary force that shapes the gene functions.

\section{Results}

Identification of ZNF280BY and ZNF280AY gene families

BTAY-expressed sequences were enriched by hybridizing a mixed testis CDNA with a micro-dissected, PCR amplified, biotin-labeled BTAY probe $[39,43]$. The enriched BTAY cDNAs were sequenced by two different technologies (see Methods). Among the 273 transcripts obtained from the Sanger sequencing, 46 ( 17\%) matched to an unmapped bovine ZNF280B mRNA (NM_001078120.1) with a sequence similarity ranging from $97 \%$ to $100 \%$. This mRNA on the Y-chr has differentiated and shares $93 \%$ sequence identity with ZNF280B on BTA17 (NM_001077935.1). Assembly of $\sim 13$ million short (36 bp) reads from the next generation sequencing resulted in $\sim 4,500$ sequence contigs (to be published separately). One of the contigs is a fulllength cDNA (1,989 bp, GenBank acc. no. HQ014563) with 99\% similarity to NM_001078120. Another 3,386 bp contig (GenBank acc. no. HQ014564) is a paralog of the predicted bovine ZNF280A (XM_596386.4 and XM_002694686.1) with a sequence similarity of $91 \%$. The bovine ZNF280B (aliases: SUHW2, 5'OY11.1) (NM_001077935.1) and ZNF280A (aliases: SUHW1, 3'OY11.1) (XM_596386.4) genes map next to each other on the distal long arm (74.307-74.326 Mb) of BTA17 (Build 4, http://www.ncbi.nlm.nih.gov/gene/517697). We have confirmed, by male-specific PCR, that the NM_001078120 mRNA and the two cDNA contigs paralogous to either ZNF280B or ZNF280A are all Ylinked in cattle (Figure 1). Therefore, we referred these two genes as ZNF280BY or ZNF280AY.

In the absence of a BTAY sequence assembly, we blast-searched ZNF280BY (NM_001078120) against all sequenced bovine bacterial artificial chromosomes (BACs) deposited in GenBank (HTGS database) and identified 252 BACs $(240$ annotated Y-BACs, the remaining $B A C s$ are draft sequences) that contains a total of 377 copies of ZNF280BY (1-5 copies/BAC). A similar search with ZNF280AY (acc. no. HQ014564) resulted in the identification of 132 BACs (124 annotated $\mathrm{Y}$-BACs, $8 \mathrm{draft}$ sequence BACs), which all 


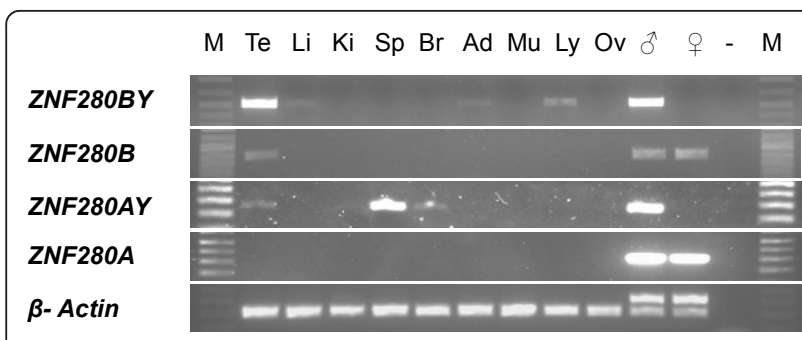

Figure 1 Tissue expression profiles of ZNF280B/ZNF280BY and ZNF280A/ZNF280AY. Both ZNF280BY and ZNF280AY were proved to be $Y$-specific genes via the male-specific PCR (lane marked with $0^{\prime \prime}$ ). ZNF280BY is expressed predominantly in the testes and slightly in liver, adrenal gland and lymph node while the autosomal ZNF280B is expressed specifically in the testis. The ZNF280AY is expressed predominantly in the spleen and low in testis and brain, while the expression of the ZNF280A was not detected among the eight tissues studied. The $\beta$-actin gene was used as positive control. Te, testis; Li, liver; Ki, kidney; Sp, spleen; Br, brain (cerebrum); Ad, adrenal gland; Mu, muscle; Ly, lymph node; Ov, ovary; o", bovine male genomic DNA control; $q$, bovine female genomic DNA control; water; M, 1 kb DNA ladder.

contained the ZNF280BY genes. All ZNF280AY-BACs harbor a single copy, except for one BAC that contains two separate copies of ZNF280AY, resulting in a total of 133 copies of $Z N F 280 A Y$. These results suggest that both $Z N F 280 B Y$ and $Z N F 280 A Y$ are multi-copy gene families on BTAY.

Point mutations and insertions/deletions (indels) were found to be present in many of the ZNF280BY copies based on sequence alignment and open reading frame (ORF) analyses, leading to 241 copies with short or no ORFs. Thus, they are pseudogenes. The remaining 136 copies, in which their ORF varied from 222 aa to 543 aa, were predicted to be active at the transcription level using Splign program [44] (Additional file 1). Among all potential active ZNF280BY loci, 113 contain the normal full-length mRNA of 1,954 bp (acc. no. GU144303, Figure 2, type A), and encode a peptide of 543 aa, which is $87 \%$ identical to the ZNF280B protein on BTA17 (NM_001077935, 545 aa). The remaining 23 loci encode peptides of 222 to 469 aa, resulted from nonsense mutations or indels (Additional file 1). Two of the short peptides, 431 aa (type B, acc. no. GU144304) and 424 aa (type C, acc. no. GU144305), were investigated in details (Figure 2). All ZNF280BYs have two exons with the coding segment (CDS) in exon 2 . The only intron in the ZNF280BY family is located in the 5'-UTR region, $71 \mathrm{bp}$ upstream of the start codon, and varies in size ranging from 9.1 to $31.7 \mathrm{~kb}$ among type $\mathrm{A}, \mathrm{B}$, and $\mathrm{C}$. The first exon of type $C$ does not share any homology with type A or B (Figure 2). RACE (rapid-amplification of cDNA ends) and RT-PCR analyses demonstrated that the type B contains a $13 \mathrm{bp}$ insertion at nt 1247 within the CDS, leading to a frame shift and a stop codon (TAA) at nt 1293, and hence, a shorter peptide of 431 aa (Figure 2). Type $C$ has an 8 bp deletion at nt 1218, resulting in a premature stop codon (TAA) at nt 1273 and a 424 aa peptide. In type $B$ and $C$, only three and two zinc finger motifs were detected, respectively, while the normal ZNF280BY (type A) has four zinc finger motifs.

A series of analyses were carried out to verify whether the predicted active loci of ZNF280BY are transcriptionally active. First, pairwise alignment of the ZNF280BY cDNA sequences obtained from the Sanger sequencing

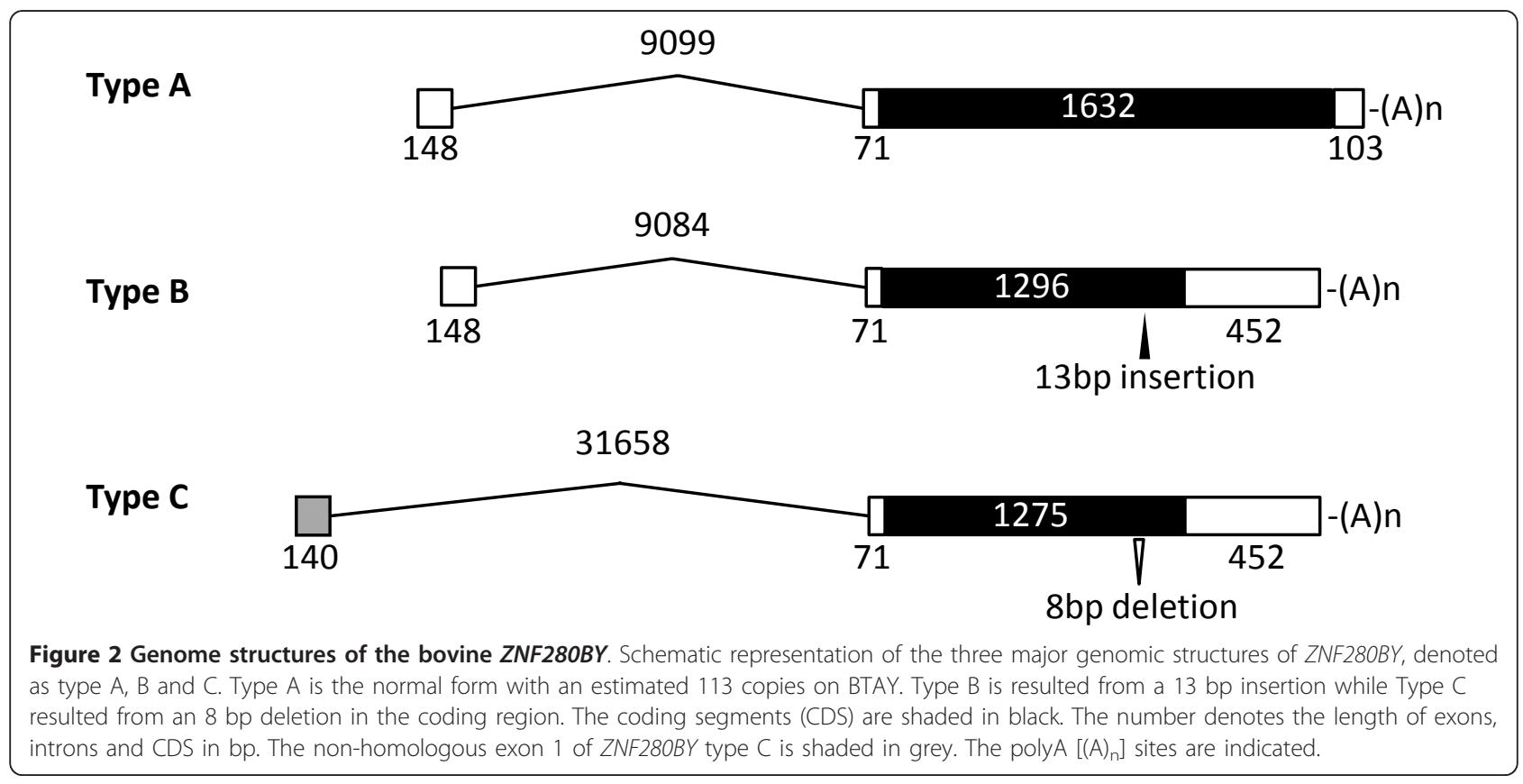


with the Y-BAC genomic sequences identified 28 unique cDNAs that match perfectly to one or more type A sequences (a total of 80 ), and two additional unique cDNAs matched to type B and C, indicating at least 82 loci of ZNF280BY are expressed in bovine testes (Additional file 2). Second, alignment of the ZNF280BYmatched Illumina reads (pair-end, $2 \times 36 \mathrm{bp}$ ) to each of the predicted $Z N F 280 B Y$ loci revealed that at least 96 loci are transcriptionally active (Figure 3A, Additional file 3). Since the results from Sanger sequencing and Illumina sequencing overlap $\sim 80 \%$, they complement each other. Third, 5'- and 3'-RACE confirmed the expression of the ZNF280BY type B and C. Finally, multiple alignment of promoter sequences indicated that ZNF280BY type A promoters are highly conserved ( $>98 \%$ similarity). These results collectively suggest that all predicted ZNF280BY loci on BTAY may be transcriptionally active.
For the bovine ZNF280AY gene family, the ZNF280AY cDNA (acc. no. HQ014564) contains a short ORF (113 aa). Further analysis of all 133 ZNF280AY genomic sequences predicted short ORFs ranging from 100 to 262 aa, which are less than half the length of the protein encoded by ZNF280A (538 aa). Therefore, we speculate that all ZNF280AY loci on BTAY were pseudogenized. However, our Illumina sequence analysis indicated that as many as 91 ZNF280AY loci (with an average length of $2620 \mathrm{bp}$, ranging from $1656 \mathrm{bp}$ to $3386 \mathrm{bp}$ ) could be transcriptionally active, and that 51 of them were unquestionably expressed as they matched $100 \%$ with unique read pairs (Figure 3B, Additional file 3).

\section{Distribution of ZNF280BY and ZNF280AY on BTAY}

The distribution/duplication patterns of the ZNF280BY and $Z N F 280 A Y$ loci on BTAY were identified by assembling a contig using the ZNF280BY/AY-containing

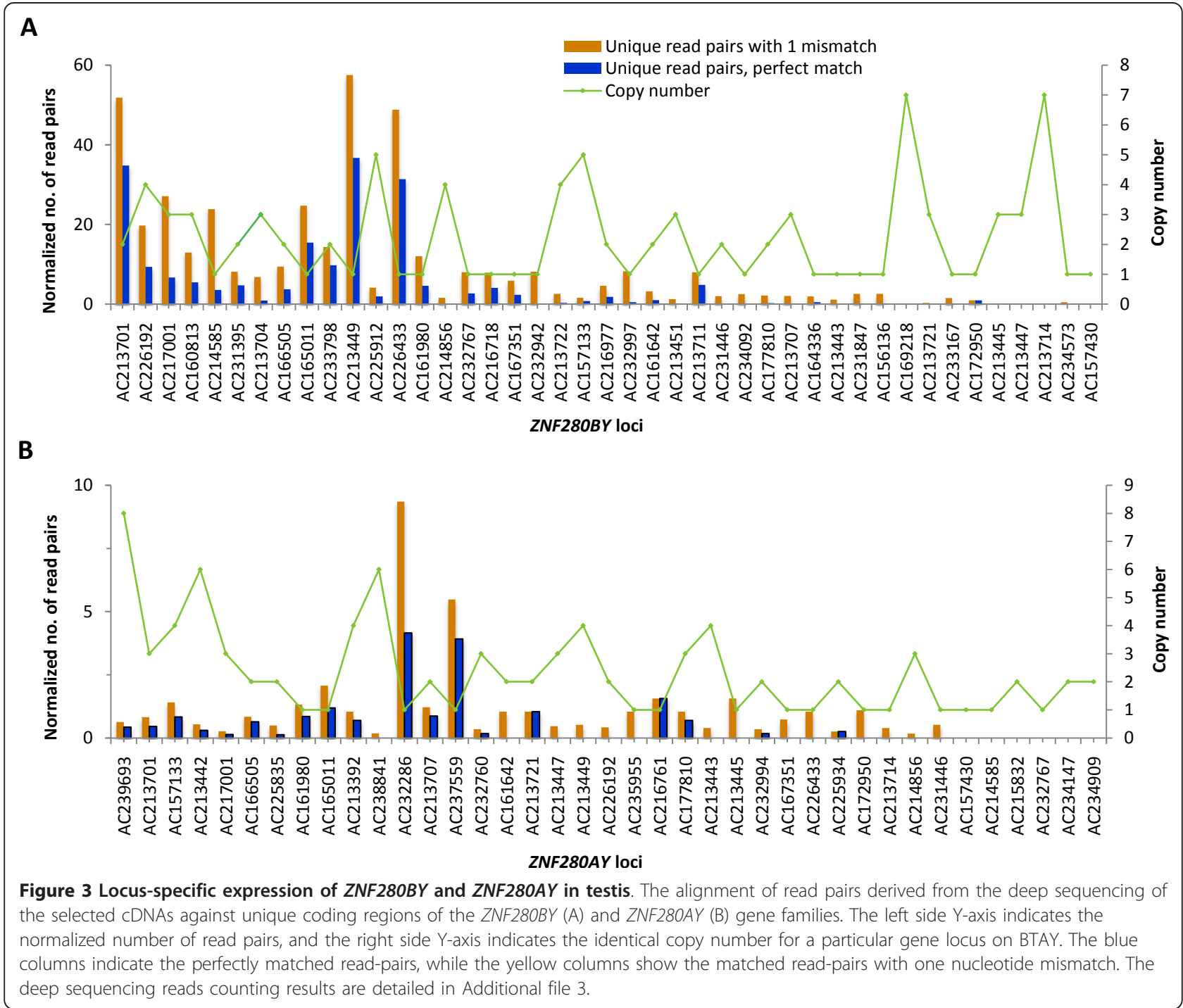


BACs deposited in GenBank. These BACs were assembled under stringent criteria that assured overlaps between BACs were $\geq 30 \mathrm{~kb}$ in size with $\geq 99.99 \%$ sequence identity. We obtained a $1.2 \mathrm{Mb}$ contig of nine BACs using Sequencher 4.8 (Genecodes, Ann Arbor, MI) (Figure 4, Additional file 4) that contained 11 loci of ZNF280BY (Figure 4), of which three were potentially coding and shared the same structure as ZNF280BY type A, while the remainder were pseudogenes. Interestingly, each active $Z N F 280 B Y$ is accompanied by a pseudo ZNF280AY, forming a ZNF280BY-ZNF280AY block with a $19 \mathrm{~kb}$ interval. The HSFY (heat shock transcription factor, Y-linked) and TSPY (testis-specific protein, $Y$-linked) gene family also reside within this contig and amplified similarly to ZNF280BY (Figure 4). The 1.2 $\mathrm{Mb}$ contig may represent a typical ampliconic region reflecting the redundant nature of BTAY DNA.
Interspersed repeats comprise $\sim 58 \%$ of the $1.2 \mathrm{Mb}$ contig and contain a high density of long interspersed repetitive elements (LINEs) and retrotransposable elements (RTEs), but low density of short interspersed repetitive elements (SINEs), thus consistent with a previous report on the bovine genome [35]. Two major directed repeats (DRs) are present in this region: DR1 and DR2 (Figure 4). DR1 contains three $110 \mathrm{~kb}$ repeat units (DR1-1, -2, and -3 ), which are $99.40 \%$ similar without considering gaps. DR1 has one ZNF280BY pseudogene in each repetitive unit. DR1-1 and DR1-3 share an extra $65 \mathrm{~kb}$ extended repeat with $99.70 \%$ similarity that contains one active $Z N F 280 B Y$. DR2 contains two $64 \mathrm{~kb}$ units which are $99.50 \%$ similar, as well as pseudogene copies of ZNF280BY. There are also two inverted repeats (IRs), IR1 and IR2, over $99.50 \%$ similar (Figure 4), which span $60 \mathrm{~kb}$ (30 kb per arm) and $134 \mathrm{~kb}$ (67 kb per arm),

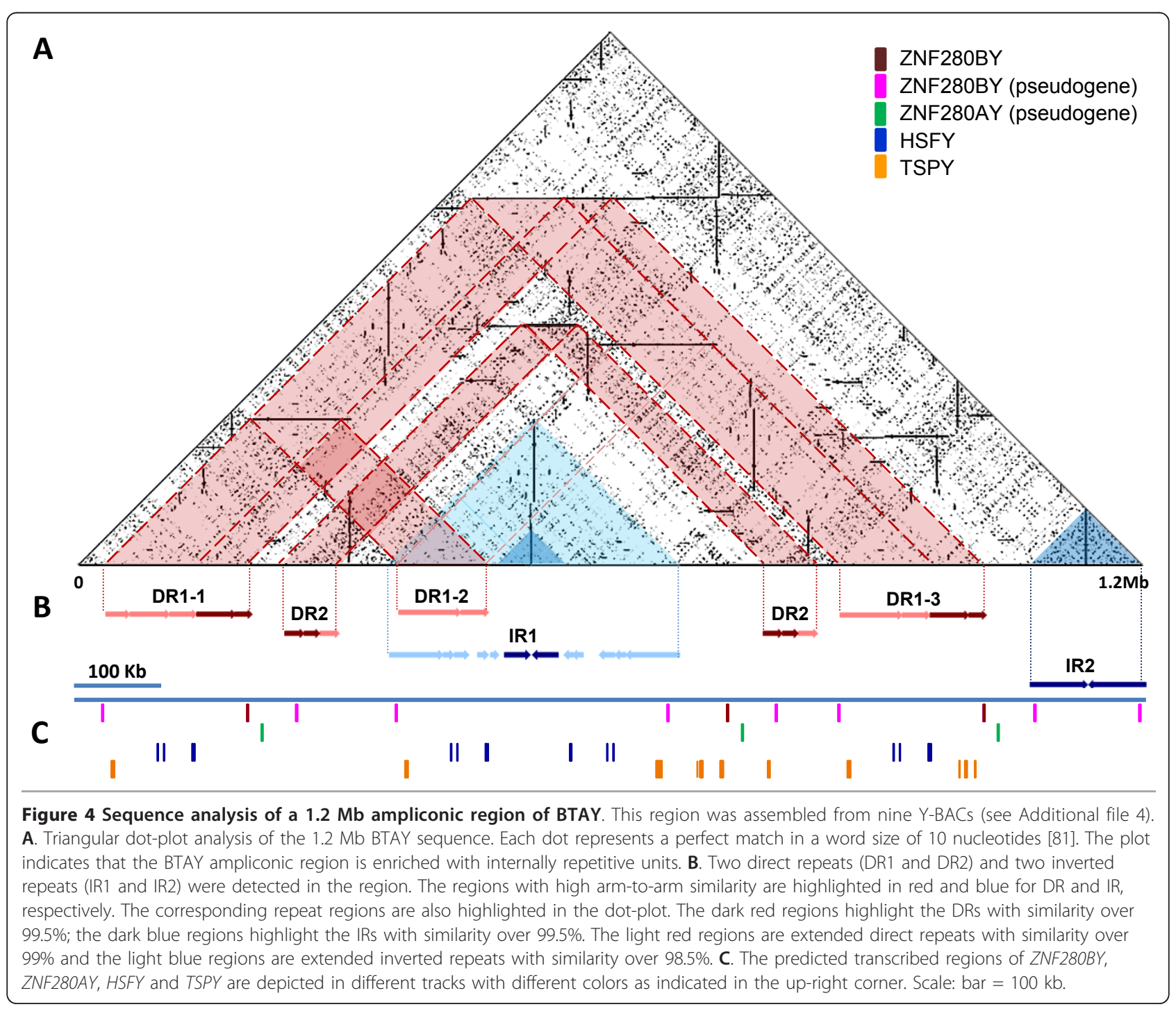


respectively. One pseudogenized $Z N F 280 B Y$ was detected in each arm of IR2, but no ZNF280BY sequence was present in IR1. However, when the identity threshold of IR1 was lowered to $98.50 \%$, we were able to expand the length of IR1 to $500 \mathrm{~kb}$ and identify a ZNF280BY pseudogene in each arm. The $1.2 \mathrm{Mb}$ contig apparently contains multiple internally repeat units, with ZNF280BY, ZNF280AY, HSFY and TSPY representing the major gene families (Figure 4).

The origin of the ZNF280BY-ZNF280AY block

In order to gain insight into the evolution of the ZNF280BY and ZNF280AY gene families, we retrieved
ZNF280B/BY and ZNF280A/AY orthologous sequences from 10 mammalian species available to date (Figure 5, Additional file 5) and conducted phylogenetic analysis. We found that the autosomal ZNF280B-ZNF280A gene block on BTA17 is highly conserved among all sequenced eutherians (except for mouse, rat and elephant), including human, chimpanzee, macaque, cow, dog, pig, and guinea pigs, and even in non-placental vertebrates (opossum, chicken, frog, and zebrafish) (Additional file 6). However, ZNF280BY/AY orthologs were identified only in bovid (cattle and sheep) Y-chrs. The Ovis aries $Y$ chromosome repeat region OY11.1 DNA sequence (acc. no. U30307.1) was first deposited in

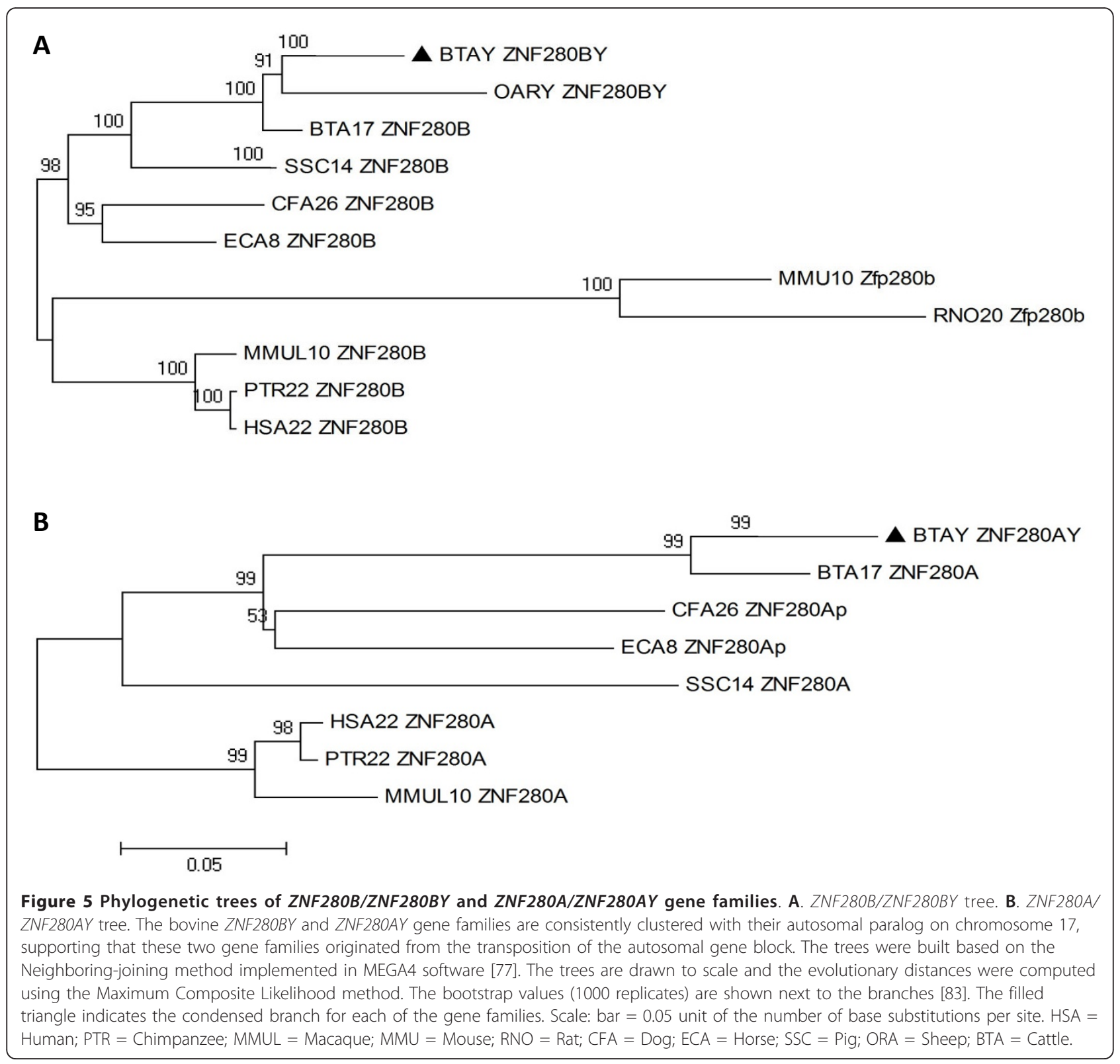


GenBank in 1995, and confirmed by fluorescent in situ hybridization (FISH) to be conserved throughout Bovidae [45].

The OY11.1 repeat sequence covers the ZNF280B (5'OY11.1), but not the ZNF280A (3'OY11.1) (http:// www.ncbi.nlm.nih.gov/sites/gene) sequence. The similarity between the ovine and bovine $Z N F 280 B Y$ is $88 \%$ at the nucleotide level and $86 \%$ at the protein level. Due to the unfinished ovine genome sequencing, we were not able to retrieve the ovine $Z N F 280 B, Z N F 280 A$ and ZNF280AY sequences in this study.

We built phylogenetic trees (Figure 5) for both gene families using neighbor-joining (NJ) and maximumlikelihood (ML) methods. The topologies were consistent between the $\mathrm{NJ}$ and $\mathrm{ML}$ tree. All predicted ZNF280BY (type A, B, and C) cDNAs (Additional files 1 and 2) were grouped in a single cluster (Figure $5 \mathrm{~A}$ ). The bovine $Z N F 280 B Y$ gene family together with the ovine ZNF280BY (OY11.1) were clustered with the bovine BTA17 ZNF280B and formed one clade with a perfect bootstrap support (Figure 5A). The autosomal orthologs of the bovine $Z N F 280 B$ in eight mammalian species were clustered in a different clade, also with a strong bootstrap support (95-100\%) (Figure 5A). The phylogenetic tree of the bovine $Z N F 280 A / Z N F 280 A Y$ (Figure 5B) is very similar to the one of $Z N F 280 B / Z N F 280 B Y$, although mouse and rat were excluded in the analysis as their orthologous sequences were not available. The facts that the $Z N F 280 B / Z N F 280 A$ gene block is located in a region of conserved synteny in eutherians and that the ZNF280BY and ZNF280AY gene families are present in bovid only, strongly suggest that the Y-linked families were a transposition of the autosomal (BTA17) block. This autosome-to-Y transposition event occurred most likely before the divergence of cattle and sheep, which was estimated to be 19.6 Mya [46].

We estimated the age of the active ZNF280BY loci by using the bovine and ovine $Z N F 280 B Y$ sequences with the neutral rate estimates as the molecular clock (Figure 5A). The mean Ks value between bovine and ovine ZNF280BY is 0.1517 . The maximum pairwise $\mathrm{Ks}$ value of the most distant ZNF280BY locus (AC172950) to the remaining active loci in bovine is 0.0443 . Based on the previous estimation of the divergence time of 19.6 Mya between the two species [46], we estimated that the duplication events for the current active ZNF280BY loci occurred approximately 5.7 Mya $(0.0443 / 0.1517 \times 19.6)$ [47].

\section{The expression profile of ZNF280BY and ZNF280AY}

RT-PCR analyses revealed that ZNF280BY expression is predominant in testis but low in liver, adrenal gland and lymph node, while the autosomal ZNF280B expression is specific to testis (Figure 1). The expression of ZNF280AY pseudogenes is high in spleen but low in testis and brain, while the ZNF280A expression was not detected among the nine tissues tested (Figure 1).

In situ hybridization (ISH) with ZNF280BY indicated that the sense and antisense RNA of this gene are expressed in adult testis (Figure 6). ZNF280BY sense RNA was widely expressed (Figure 6A), but the antisense RNA was detected only in the spermatids (Figure 6B).

The expression of the sense and antisense RNA of the ZNF280BY over different stages of testis development (4 20-day, 3-month, 8-month and >24-month) by qRTPCR indicated the expression of $Z N F 280 B Y$ sense RNA increased significantly with age $(\mathrm{p}<0.05)$. In contrast, ZNF280BY antisense RNA expression was stable during testis development (Figure 7). It is noteworthy that expression between qRT-PCR replicates for the same individual at each stage (technical replicates) were highly consistent, whereas the levels between different individuals (3 biological replicates) varied, resulting in relatively high standard deviations (Figure 7).

To address the question of whether different loci of the ZNF280BY families on BTAY are differentially expressed, we counted the number of read-pairs unique to a given locus (read-pairs that are shared by two or more loci were not counted). As shown in Figure 3A, different loci of ZNF280BY are differentially expressed with as much as 60 -fold changes. Similar analysis to the different copies of the ZNF280AY pseudogenes on BTAY indicated that their expression also varied as much as 10 -fold (Figure 3B). However, the expression level of the ZNF280AY pseudogenes is much lower (one-sixth) compared to the ZNF280BY genes (Figure 3), which is consistent with the RT-PCR analysis (Figure 1).

\section{Discussion}

\section{Autosome to Y-chr transposition}

Autosome-to-Y transposition of male fertility genes is a recurrent theme in mammalian Y-chr evolution [48]. As a result, the content of male-beneficial genes in MSY has increased in spite of a 95\% loss of the ancestral $\mathrm{Y}$-chr genes due to the absence of recombination. Autosome-to-Y transposition events apparently occurred separately in different lineages with newly acquired Y-chr genes from diverse genomic locations [20]. This resulted in lineage-specific $\mathrm{Y}$-chr genes (families) that account for a significant portion of the gene (and sequence) variation among mammalian Y-chrs. The human $D A Z$ gene family was derived from the transposition of the autosomal $D A Z L$ that maps to the subtelomeric region on HSA3p24.3 [48], while CDY arrived on the human Y-chr through retrotransposition of CDYL on HSA6 $[4,49]$ during primate evolution. The mouse Ssty 1 was derived from a retroposition of an autosomal gene Spin1 on MMU13 [18]. The feline FLJ36031 and TETY1 gene families originated through 

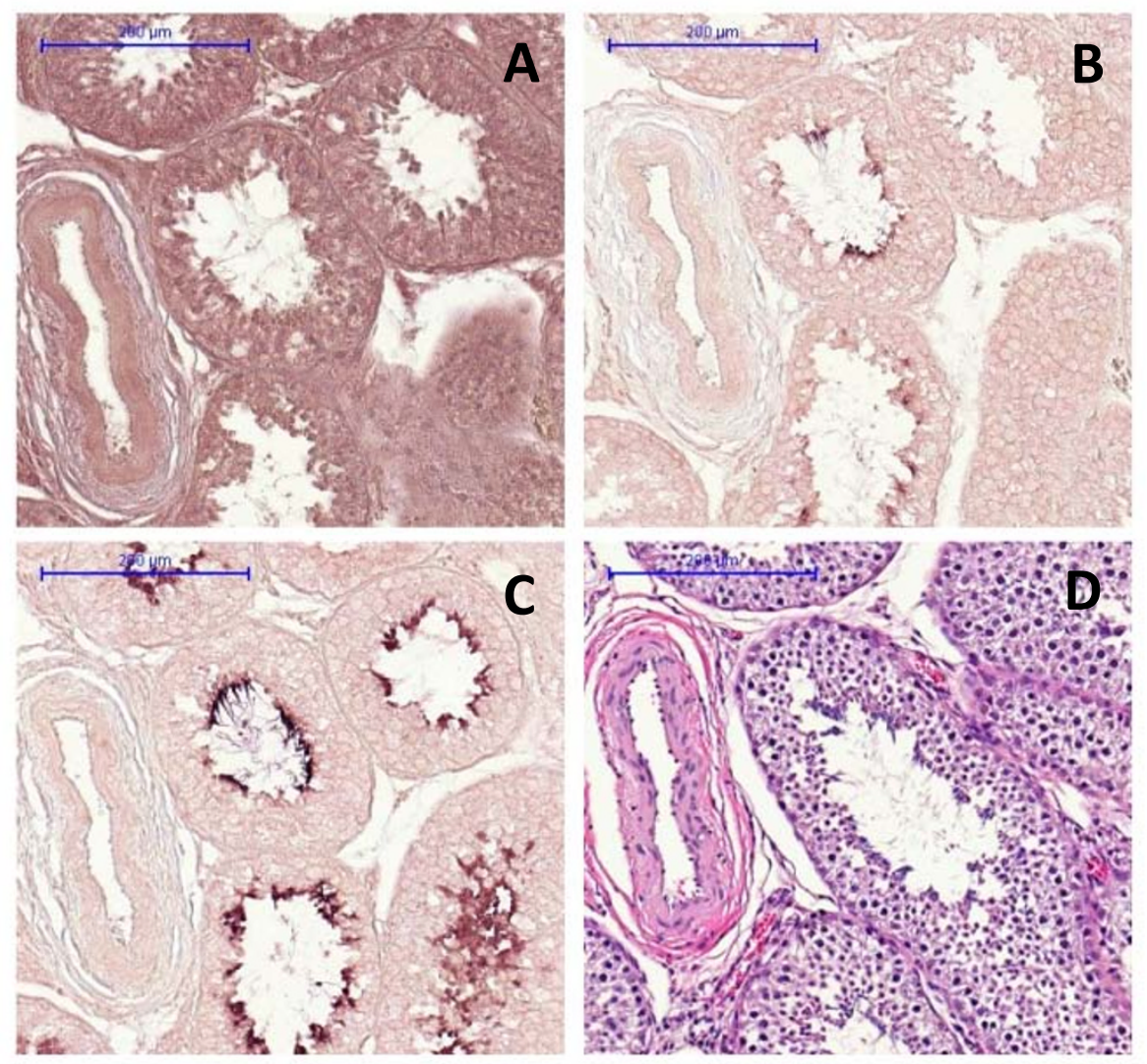

Figure 6 Tissue localization of the bovine ZNF280BY transcript in adult testis. The sense and antisense RNA of ZNF280BY are expressed in adult testis. A. The ZNF280BY sense RNA is expressed widely and evenly across all cell types in the seminiferous tubules. B. The antisense RNA of ZNF280BY was only detected in spermatids. Sense (A) and antisense (B) RNA of ZNF280BY were detected by the corresponding DIG-labeled cRNA probes. C. The bovine Protamine gene was used as the positive control, and there is no antisense mRNA of Protamine detected in the bovine testis [34]. D. The Haematoxylin and Eosin (H\&E) staining was shown. Scale: bar $=200 \mu \mathrm{m}$.

autosome-to-Y transposition before and after the divergence of cats and dogs, respectively [20].

In addition to autosome-to-Y transpositions, a massive $\mathrm{X}$-to-Y sequence transposition has also been observed in humans, which occurred after the human and chimpanzee divergence ( 3-4 Mya) and resulted in an X-transposed sequence block on the $\mathrm{Y}$ that contains two single-copy genes, TGIF2LY and PCDH11Y [4]. This block of the $Y$-chr sequence still shares a high similarity with the X-counterpart ( $99 \%)$ though it does not recombine during meiosis [4].

We identified two novel Y-chr gene families, ZNF280BY and ZNF280AY, which are present on both bovine and ovine $Y$-chrs, but not on non-bovid Y-chrs investigated to date. We propose that the ZNF280BY/ $A Y$ gene families are lineage-specific in Bovidae. Phylogenetic analysis of the ZNF280B/BY and ZNF280A/AY family (Figure 5) strongly support that the bovine $Z N F 280 B Y / A Y$ originated from the autosomal genes, $Z N F 280 B / A$, on BTA17. Unlike the human DAZ and feline TETY1 and FLJ36031 genes, where a single autosomal gene is involved in the transposition, the bovine ZNF280B/A transposed to the Y-chr as a block. This autosomal block is located in the sub-telomeric region that could be a hotspot for segmental duplication [50].

\section{ZNF280BY-ZNF280AY amplification and the "birth-and-} death" evolution

The distribution pattern and differences in copy number suggest that ZNF280BY-ZNF280AY was differentially amplified on BTAY after transposition. We identified 136 active $Z N F 280 B Y$ and 241 pseudogenes from BTAY-BACs, and estimated that the oldest active ZNF280BY locus emerged via a duplication event $\sim 5.7$ Mya. This is significantly later than the estimated divergence time of 19.6 Mya between cattle and sheep [47]. The results lead us to believe that the progressive amplification of the bovine ZNF280BY follows the "birthand-death" model of evolution [51]. Based on this model, new ZNF280BY loci were created by repeated 


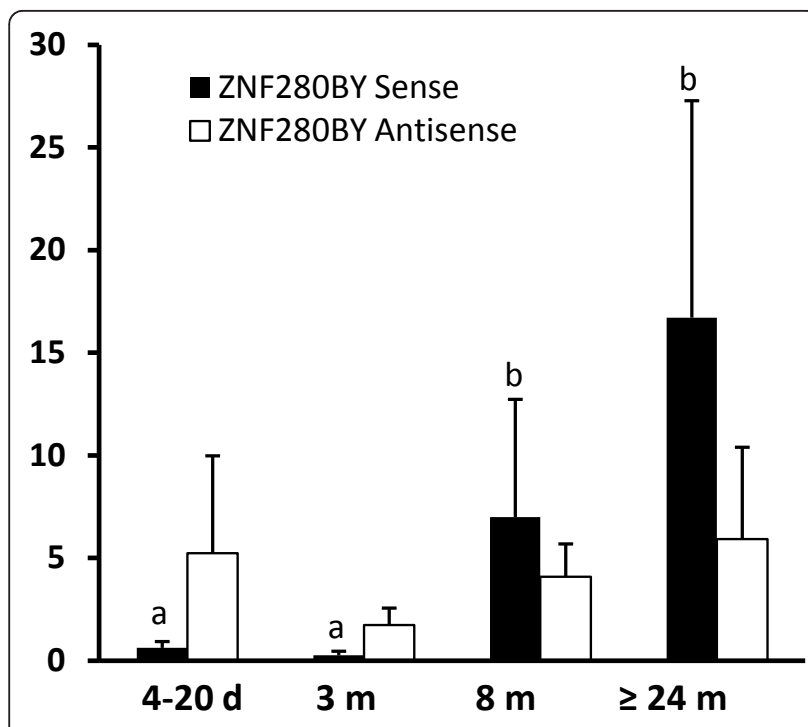

Figure 7 Expression of ZNF280BY sense and antisense RNA at different developmental stages of testis. The relative expression levels of the ZNF280BY sense and antisense RNA at different ages of testis (X-axis), measured by the strand-specific qPCR, were normalized by the $18 \mathrm{~S}$ rRNA (Y-axis). Values are means \pm SD of triplicates. The expression of sense RNA increased gradually with age. In contrast, the ZNF280BY antisense RNA had a stable expression level except for a decrease in 3 month old testis. The significant expression difference was identified when $p \leq 0.05$ by the ANOVA analysis and denoted by $(a, b)$ where the gene expression at stages of (b) is significantly different from that at (a).

gene duplication with some duplicated genes maintained on the BTAY and others lost due to mutation and degeneration, as active gene copies might cooperate to increase the efficiency of male fertility and damage to a few copies would not significantly impact the biological system [52]. Each of the three active ZNF280BY loci in the $1.2 \mathrm{Mb}$ region is accompanied by a $Z N F 280 A Y$ pseudogene (Figure 4). If this is true for all 136 active ZNF280BY loci, we should expect to identify a minimum of $136 Z N F 280 A Y$ pseudogenes. Interestingly, the observed 133 copies of ZNF280AY pseudogenes in this study are very close to the expected number, but we do not, as yet, know whether co-amplification of the $Z N F 280 B Y-Z N F 280 A Y$ or the loss of the ZNF280AY in the gene pair has any role in the activity of $Z N F 280 B Y$.

A significant feature of the human MSY is the eight palindromes (24 $\mathrm{kb}$ to $2.9 \mathrm{Mb}$ ) with arm-to-arm sequence identities $\geq 99.94 \%$ [4,53]. Y-to-Y gene conversion between the paired-genes on each arm occurs frequently in humans, constraining sequence divergence and maintaining the critical functions of the MSY genes [4,53]. Pairwise comparisons of all available BTAY-BACs and the assembly of a $1.2 \mathrm{Mb}$ ampliconic region located in MSY revealed several palindrome-like inverted repeats with an arm-to-arm identity of $99.85 \%$ (Figure 4 ).
The occurrence of palindrome-like IRs indicates that the Y-Y gene conversion mechanism may apply to these gene families. When the criteria for sequence assembly was lowered from $99.99 \%$ to $99.85 \%$ identity, and the minimum overlap size between BACs decreased from $30 \mathrm{~kb}$ to $20 \mathrm{~kb}$, we obtained another large contig $(\sim 2.2 \mathrm{Mb})$ from different Y-BACs displaying similar dot-plot and repeat pattern as the $1.2 \mathrm{Mb}$ contig (Figure 4). It appears that the majority of the bovine MSY ampliconic region is enriched with internally repetitive units containing ZNF280BY, ZNF280AY, HSFY and TSPY.

\section{Locus-specific expression of multi-copy genes on the Y-chr}

One of the most important features of mammalian $\mathrm{Y}$-chrs is the multi-copy gene families that are exclusively expressed in testis and play essential roles in spermatogenesis and male fertility. The largest $\mathrm{Y}$-gene family reported to date is TSPY, which is conserved on most of the mammalian Y-chrs. The human Y-chr harbors 20-70 copies of TSPY [4,54], while the bovine Y-chr has 50-200 copies [55-57]. Unlike the human TSPYs that are clustered as a tandem array in a narrow region $(\sim 700 \mathrm{~kb})$ on Yp [4], the bovine TSPYS spread over the majority of the MSY ampliconic region. Recent studies in TSPY copy number variation (CNV) has indicated that CNV significantly influenced spermatogenic efficiency in men $[58,59]$. However, efforts to study the expression profile of the multi-copy Y-chr genes have been impeded because of the high similarity (95-100\%) among different copies (loci). In this work, we have successfully applied the deep sequencing technology to analyze the locus-specific expression of the ZNF280BY and ZNF280AY gene families. We believe that there are two important advantages with the deep sequencing approach. First, by counting the perfectly matched read pairs, one can directly evaluate the expression level of any given locus (except for those loci that are 100\% identical). Second, one can also compare the average expression level among gene families or individuals (biological replicates) based on read counts. We expect that the combination of $\mathrm{CNV}$ and locus-specific expression analyses on these Y-gene families, including ZNF280BY, ZNF280AY, HSFY, and TSPY, will help us to understand how multi-copy gene families regulate and function during spermatogenesis.

\section{Potential function in spermatogenesis}

Although zinc finger proteins are among the most abundant and functionally diverse in mammalian genomes [60], little is known of the functions of ZNF280B (SUHW2) in mammals. The Drosophila ortholog, suppressor of Hairy-wing $[\mathrm{Su}(\mathrm{Hw})]$, is a transcriptional regulator. The $\mathrm{Su}(\mathrm{Hw})$ protein has been found to bind an 
insulator element within a gypsy retrotransposon to mediate enhancer-blocking of gypsy towards target genes [61,62]. The conserved syntenic block ZNF280BZNF280A on HSA22 is located within the lambda light chain loci and is reportedly associated with immune responsiveness $[63,64]$.

The discovery of the autosome-to- $Y$ transposition and subsequent amplification of the ZNF280BY-ZNF280AY gene block on BTAY led us to suggest that the two gene families may play an essential role in spermatogenesis. A comparable example is the Ssty1 gene family in mice which is significantly amplified (>100 copies) after retroposing to the Y-chr and is expressed specifically in spermatids with a function in sperm differentiation $[65,66]$. As expected, we found that the bovine ZNF280BY family predominantly and $Z N F 280 B$ specifically expressed in testes (Figure 1). The significant age related elevation of ZNF280BY levels (Figure 7) may be associated with the maturation of the bovine testes and cell proliferation throughout spermatogenesis. Antisense RNA may play a role in regulating the expression of $Z N F 280 B Y$ during spermatogenesis (Figure 6A \&6B). The antisense transcripts of $Z N F 280 B Y$ were over-expressed relative to sense transcripts in testes $\leq 3$ months of age (Figure 7 ). This observation is in contrast to a previous report that found lower antisense versus sense transcript levels in genes expressed in germ cells [67]. The antisense RNAs of the three Y-related and testis-expressed genes in cattle, including $Z N F 280 B Y, D D X 3 Y$ and $C D Y L$, all appear to be expressed in the late stage of spermatocytes and/or spermatids, indicating that antisense RNA is important in regulating bovine spermatogenesis $[34,68]$.

\section{Conclusions}

The identification of lineage-specific Y genes recapitulates the diversity of $\mathrm{Y}$ gene content and signifies the importance of comparative studies of the mammalian $\mathrm{Y}$-chr. This study provides a base for further research on Y-chr evolution and male-fertility. As the expression of the bovine ZNF280B/ZNF280BY and ZNF280A/ $Z N F 280 A Y$ is predominant in the testis, their autosomal orthologs in other eutherians may play roles in spermatogenesis. We believe that additional functional analysis of ZNF280B/ZNF280BY and ZNF280A/ZNF280AY will offer insights into gene regulation in spermatogenesis, the evolution of the mammalian $\mathrm{Y}$-chr and advance the assembly of the bovine $\mathrm{Y}$-chr sequence.

\section{Methods}

\section{RNA extraction and cDNA synthesis}

Total RNA was extracted from bovine testicular tissue at 4 days, 20 days, 3 months, 8 months and $\geq 2$ years of age with Trizol ${ }^{\circledR}$ reagent (Invitrogen, Carlsbad, CA, USA). Equal amounts of total RNA from different age groups were pooled, treated twice (before and after mRNA purification) with the DNase I (Ambion, Austin, Texas, USA) and messenger RNA was purified from the pooled total RNA (Oligotex; Qiagen, Valencia, CA, USA). First strand cDNA was synthesized with random hexamers and oligo$\mathrm{T}$ primers and SuperScript ${ }^{\mathrm{TM}}$ III reverse transcriptase (Invitrogen, Carlsbad, CA, USA) and blunt-ended double-stranded cDNA was developed as described [69]. Adaptors, which are annealed phosphorylated oligonucleotides 1 (5'-CTGAGCGGAATTCGTGAGACC-3') and 2 (5'-CCAGAGTGCTTAAGGCGAGTCAA-3') (IDT, Coralville, IOWA, USA), were attached to cDNA using T4 polynucleotide kinase (NEB, Ipswich, MA, USA) [42]. Adaptor-ligated cDNA products were used for direct testis cDNA selection.

\section{Y-chr DNA probe labeling}

Fragments of BTAY DNA were isolated by a microdissection approach [70], and were labeled with biotin16-dUTP (Roche, Indianapolis, IN, USA) using nick translation (Roche, Indianapolis, IN, USA) following a method described by Del Mastro and Lovett [42]. A reaction mixture containing DNA polymerase I, DNase I, 60 ng whole chromosome amplified (WCA) Y fragments, biotin-16-dUTP $0.2 \mathrm{nmol}$, dNTPs $4 \mathrm{nmol}$, ${ }^{32} \mathrm{P}$-dCTP (Perkin Elmer, Waltham, Massachusetts, USA) $10 \mu \mathrm{Ci}$, was incubated in $15^{\circ} \mathrm{C}$ water bath for $90 \mathrm{~min}$. The biotinylated products were purified through a Probquant G-50 spin column (GE Healthcare, Buckinghamshire, UK) and labeling efficiency was determined by incorporation of ${ }^{32} \mathrm{P}-\mathrm{dCTP}$ as described [42].

\section{Direct testis cDNA selection and sequencing}

Direct testis cDNA selection was carried out as described [42]. After a pre-hybridization step with bovine Cot-1 DNA (Applied Genetics Laboratories, Melbourne, FL, USA) to block the repetitive elements, the adaptor-ligated cDNA was hybridized with the biotinylated BTAY probe for $50 \mathrm{hr}$ in $0.75 \mathrm{mM} \mathrm{NaCl}, 20 \mathrm{mM}$ sodium phosphate ( $\mathrm{pH} 7.2), 5 \mathrm{mM}$ EDTA, $5 \times$ Denhardt's solution and $0.1 \%$ SDS. Hybridized cDNA was isolated with streptavidin paramagnetic Dynabeads M-280 (Invitrogen, Carlsbad, CA, USA) per the manufacturer's instructions. After washing twice with wash solution I $(1 \times \mathrm{SSC}, 0.1 \% \mathrm{SDS})$ for $15 \mathrm{~min}$ at room temperature to remove the unbound $\mathrm{CDNAs}$, and washing with wash solution II $(0.1 \times \mathrm{SSC}, 0.1 \% \mathrm{SDS}) 4$ times, $20 \mathrm{~min}$ each at $65^{\circ} \mathrm{C}$ to remove the non-specifically bound cDNAs, the selected cDNA was eluted from the beads by $1 \times \mathrm{SSC}$ at $95^{\circ} \mathrm{C}$ for $5 \mathrm{~min}$, and then amplified by PCR with the adaptor oligo 1 as the primer. Selection efficiency was assessed by qPCR with Y-linked genes, $S R Y$ and $D D X 3 Y$, as positive controls and, $\beta$-Actin and $C D Y L$, as negative controls. PCR products were cloned 
using a TOPO-TA cloning kit (Invitrogen, Carlsbad, CA, USA). A total of 2,208 random clones were grown overnight at $37^{\circ} \mathrm{C}$ in $2 \mathrm{ml}$, 96-deep-well culture plates. Dotblotting the clones with BTAY fragments yielded 753 (most likely) non-redundant clones. Plasmid DNA was purified by alkaline lysis (Qiagen, Valencia, CA, USA), and sequenced on an ABI-3730XL DNA analyzer at the Pennsylvania State University Genomics Core Facility.

\section{RT-PCR}

Total RNA was extracted from eight different tissues (including testis, liver, kidney, spleen, cerebellum, adrenal gland, longissimus muscle, and lymph node) of a two years old bull and ovarian tissue from a mature cow, treated with DNase I (Ambion, Austin, TX, USA) and reverse transcribed using SuperScript ${ }^{\mathrm{TM}}$ III First-Strand Synthesis System (Invitrogen, Carlsbad, CA, USA). RT-PCR was performed with gene-specific primers (GSPs) (Additional file 7) in a $20 \mu \mathrm{l}$ volume containing $10 \mathrm{ng}$ cDNA, $200 \mu \mathrm{M}$ dNTPs, $1.5 \mathrm{mM} \mathrm{MgCl}_{2}, 2.5 \mu \mathrm{M}$ of each primer and 1 unit Taq DNA polymerase (Bioline, Taunton, MA, USA). The PCR conditions were: $94^{\circ} \mathrm{C}$ for $7 \mathrm{~min}$ followed by 35 cycles each of $95^{\circ} \mathrm{C}$ for $40 \mathrm{sec}, 55-65^{\circ} \mathrm{C}$ for $40 \mathrm{sec}, 72^{\circ} \mathrm{C}$ for $40 \mathrm{sec}$, with a final extension at $72^{\circ} \mathrm{C}$ for $7 \mathrm{~min}$. Products were resolved on $1.5 \%$ agarose gels with ethidium bromide in $1 \times$ TAE buffer.

\section{RACE}

Total RNAs from bovine testis $(4 \mathrm{~d}, 20 \mathrm{~d}, 3 \mathrm{~m}, 8 \mathrm{~m}$, and 2 years of age) were used for 5' and 3' rapid amplification of cDNA ends (RACE). The RACE cDNA template was synthesized using the ExactSTART Eukaryotic mRNA 5'- \& 3'-RACE kit (Epicentre, Madison, WI, USA) according to the manufacturer's protocol, and amplified by PCR with kit supplied primers 1 and 2 . The 5'-end of ZNF280BY was amplified by a nested PCR with Primer 1 and GSPs (Additional file 7). PCR was performed in $20 \mu \mathrm{l}$ with $10 \mathrm{ng}$ of cDNA (or $1 \mu \mathrm{l}$ of the first PCR products), $0.25 \mu \mathrm{M}$ of both primers, 200 $\mu \mathrm{M}$ of each dNTP, $2.25 \mathrm{mM} \mathrm{MgCl} 2,0.6 \mathrm{U}$ of hot-start DNA polymerase (Qiagen, Valencia, CA, USA) under the following cycling conditions: $15 \mathrm{~min}$ at $95^{\circ} \mathrm{C}$; 35 cycles of $40 \mathrm{sec}$ at $95^{\circ} \mathrm{C}, 40 \mathrm{sec}$ at the annealing temperature (Additional file 7), $1 \mathrm{~min}$ at $72^{\circ} \mathrm{C}$; and a final extension of $7 \mathrm{~min}$ at $72^{\circ} \mathrm{C}$. The PCR products were electrophoretically separated in 1.5\% agarose, purified with the QIAquick Gel Extraction Kit (Qiagen, Valencia, CA, USA) and sequenced using GSP primers.

\section{In situ hybridization (ISH)}

The bovine testis was fixed [71], embedded in paraffin and sectioned $(4 \mu \mathrm{M})$. Sense and antisense RNA of ZNF280BY were selected (Additional file 8) using G-PROBE software (Genetyx Co. Tokyo, Japan). The selected 120 bp probes were subjected to in vitro transcription to produce digoxigenin (DIG)-labeled cRNA with the AmpliScribe T7-Flash Transcription Kit (Epicentre, Madison, WI, USA). Uniform labeling of DIGlabeling was confirmed using the NBT/BCIP detection system (Roche Diagnostics, Indianapolis, IN, USA). ISH [72] was modified by hybridizing in 50\% formamide, $2 \times$ SSC, $1.0 \mathrm{mg} / \mathrm{ml}$ tRNA, $1.0 \mathrm{mg} / \mathrm{ml}$ salmon sperm DNA, $1.0 \mathrm{mg} / \mathrm{ml} \mathrm{BSA}, 1.0 \% \mathrm{SDS}$ and $3.0 \mu \mathrm{g} / \mathrm{ml}$ DIG-labeled RNA probe at $42^{\circ} \mathrm{C}$ for $26-64 \mathrm{hr}$. Serial tissue sections were used for antisense and sense probe hybridizations. The spermatid-specific genes Protamine 1 (PRM1) and LNE120 served as positive and negative controls.

\section{Strand-specific quantitative PCR (qPCR)}

First strand sense and antisense cDNAs were synthesized with strand-specific primers (Additional file 7) (SuperScript ${ }^{\mathrm{TM}}$ III First-Strand Synthesis System, Invitrogen Carlsbad, CA, USA) using the bovine testis total RNA ( $4-20 \mathrm{~d}, 3 \mathrm{~m}, 8 \mathrm{~m}$ and $\geq 2$ years) as templates, which were then used for the real-time qPCR. All qPCRs were performed in Power SYBR Green PCR Master Mix (Applied Biosystems, Foster City, CA) and Applied Biosystems 7500 Real-time PCR system following the manufacturer's instructions. Amplification conditions were $2 \mathrm{~min}$ at $50^{\circ} \mathrm{C} ; 10 \mathrm{~min}$ at $95^{\circ} \mathrm{C}$; followed by 40 cycles of $20 \mathrm{sec}$ at $95^{\circ} \mathrm{C}, 20 \mathrm{sec}$ at $57^{\circ} \mathrm{C}$ and $30 \mathrm{sec}$ at $72^{\circ} \mathrm{C}$. Cycle threshold (CT) acquisition used default parameters with CT values for ZNF280BY sense/antisense RNAs normalized to $18 \mathrm{~S}$ rRNA in each sample. RNA samples without reverse transcript served as the negative control. Each qPCR was conducted in duplicate on 3 independent RNA (age) samples (replicates). Significance was evaluated by one-way ANOVA using SAS (SAS Institute Inc., NC, USA).

\section{Short-read sequencing for locus-specific expression}

The selected cDNAs were subjected to mechanical fragmentation by nebulization (compressed air at 32-35 psi for 6 min on ice). All enzymes used for sequencing were obtained from Illumina, Inc. The resulting doublestranded (ds) overhang fragments were end-repaired by incubation in the presence of T4 DNA polymerase and Klenow polymerase. The polished fragments were phosphorylated by $\mathrm{T} 4$ polynucleotide kinase, followed by the addition of a single 'A' base to the 3 ' end of the bluntended phosphorylated fragments. This ' $A$ ' base prepared the DNA fragments for ligation to adapter oligonucleotides (Illumina paired-read adapters), which have an overhanging ' $\mathrm{T}$ ' base at their 3' end. Ligation products were size-selected by gel electrophoresis and purification ( $2 \%$ low-range agarose with ethidium bromide). Following 1-2 $\mathrm{hr}$ at $80-110 \mathrm{~V}$ (room temperature), the library range was visualized under brief UV and the desired 
size (200-300 bp) was excised. Purified DNA libraries were subjected to a final PCR amplification step (15 cycles). PCR conditions were an initial $30 \mathrm{sec} 98^{\circ} \mathrm{C}$ denaturation, followed by 15 cycles of: $40 \mathrm{sec}$ at $98^{\circ} \mathrm{C}, 30 \mathrm{sec}$ at $65^{\circ} \mathrm{C}, 30 \mathrm{sec}$ at $72^{\circ} \mathrm{C}$, followed by $5 \mathrm{~min}$ at $72^{\circ} \mathrm{C}$ and a final hold at $4^{\circ} \mathrm{C}$. Amplified libraries were quantitatively and qualitatively assessed by Nanodrop ND-1000 (Thermo Scientific, DE, USA) UV/Vis spectroscopy and DNA BioAnalyzer 2100 microfluidics (Agilent, CA, USA).

A total of 6,710,574 high-quality paired-end reads of $2 \times 36$ bp were generated using Illumina GAIIx from the selected cDNA. These reads were aligned to the unique $Z N F 280 B Y$ and $Z N F 280 A Y$ sequences identified through BlastClust with $100 \%$ similarity and $100 \%$ coverage as the criteria. For aligning the short-reads, the software GSNAP [73] was used as part of the Alpheus pipeline [74]. Two mismatches were allowed during the alignment step and only the reads that hit the reference uniquely were considered for counting towards locus-specific expression. Since the reads were paired-end, only the reads where both ends hit the same reference were considered. These counts were further sub-grouped under three categories: (A) both reads unique hits with 2 mismatches, (B) both reads unique hits with at least one of them being exact match and $(\mathrm{C})$ both reads unique hits \& both exact matches. The read counts in these three categories were considered a measure of expression pertaining to the specific locus.

The count values were then normalized by the transcript length ratio and number of unique sites:

$$
\frac{\text { Read counts }}{\text { Copy number }} \times \frac{\text { Average length }}{\text { Length }} \times \frac{1}{\text { Number of unique sites }}
$$

\section{Sequence alignment, gene prediction and phylogenetic tree construction}

The ZNF280BY (NM_001078120) sequence was Blasted against the annotated Y-BAC pool in NCBI (http:// www.ncbi.nlm.nih.gov/) to detect potential homologous regions on BTAY. The SIM4 program [75] was used to compare RACE and RT-PCR results with identified Y homologous regions to determine the homologs with similar intron/exon structures and consensus (GT-AG) splice sites. BlastClust (NCBI package) was used to cluster the retrieved homologs. Open reading frames of these homologs were then predicted with the GETORF program in EMBOSS [76]. Pseudogenes were distinguished from genes on the basis of premature stop codons or frameshifts.

Ks values were calculated using the Nei-Gojobori method (Jukes-Cantor correction) in MEGA4 [77,78]. All positions containing alignment gaps and missing data were eliminated only in pairwise sequence comparisons (Pairwise deletion option). Phylogenetic trees (Additional file 5) were constructed using the $\mathrm{NJ}$ and ML methods [77]. The evolutionary distances were computed using the Maximum Composite Likelihood method [79].

\section{Y-chr sequence assembly}

Sequencher 4.8 (Genecodes, Ann Arbor, MI) was used to assemble the BTAY contigs. A cutoff threshold of $\geq 99.99 \%$ sequence identity between overlapped BACs with $\geq 30 \mathrm{~kb}$ overlapped regions ensure a high quality assembly of the $1.2 \mathrm{Mb}$ contig (Figure 4, Additional file 4). The $2.2 \mathrm{Mb}$ contig was assembled under a sequence cutoff threshold set at $\geq 99.85 \%$ identity with $\geq 20 \mathrm{~kb}$ overlapped regions. Repeat elements were identified by RepeatMasker [80]. The dot-plot was produced by Gepard with a word size of 10 nucleotides [81]. Several purpose-designed scripts were coded to visualize the assembly, marker labeling and incorporate the Blast [82] and EMBOSS [76] programs.

\section{Additional material}

Additional file 1: A list of the active copies of the bovine ZNF280BY CDNA sequences and the predicted sizes of ZNF280BYpeptides. This file provides a list of the active copies of the bovine ZNF280BY CDNA sequences, the predicted ZNF280BYpeptides, and the information about the ZNF280BY loci were detected in the direct testis CDNA selection.

Additional file 2: Analyses of the ZNF280BY containing BACs. The ZNF280BY genomic structure and clusters of predicted CDNAs and protein isoforms

Additional file 3: Deep sequence reads count for locus-specific expression of the bovine ZNF280BY and ZNF280AY. Analysis of the locus-specific expression of the bovine ZNF280BY and ZNF280AY using a deep-sequencing approach.

Additional file 4: BTAY-specific BACs used for assembly of the $\mathbf{1 . 2}$ Mb contig. A list of BTAY-specific BACs used for assembly of the $1.2 \mathrm{Mb}$ contig.

Additional file 5: Sequence information for the phylogenetic trees. A list of sequences used for phylogenetic analysis.

Additional file 6: The alignment of the ZNF280B/ZNF280A gene block across 17 species. The ZNF280B/ZNF280A gene blocks are

conserved in the syntenic regions in most mammals except the rodents, where the block was rearranged in two different chromosomes (Chr4/10 in the mouse and Chr5/20 in the rat). This plot was generated based on the human Chr22 assembly (hg18). The boxes represent ungapped alignments; the lines represent gaps. This plot was generated using lastz alignment from the UCSC genome browser (http://genome.ucsc.edu/).

Additional file 7: Primer sequences for (RT-) PCR and strand-specific quantitative RT-PCR. Primer sequences designed for (RT-) PCR and strand-specific quantitative RT-PCR.

Additional file 8: Probe sequences for the testis section in situ hybridization. ZNF280BY sense and antisense CRNA probe sequences designed for the testis section in situ hybridization. Probe sequences for the bovine Protamine 1 (PRM1) gene (positive control) and LNE120 (negative control) are also included.

\section{Acknowledgements}

We thank Dr. Abel Ponce de León at the University of Minnesota for providing the micro-dissected BTAY DNA fragments, and Dr. Jon Oatley and 
Ms. Melissa Oatley at the Pennsylvania State University for providing partial RNA samples of the bovine testes for this study. We also thank the Human Genome Sequencing Center (HGSC) at Baylor College of Medicine for sequencing the BTAY BACs. We are grateful to Dr. Craig Beattie, Kateryna Makova and Melissa Wilson for their comments on the manuscript. We would also like to thank the three anonymous reviewers for their critical comments and suggestions. This work was supported by grants from USDACSREES (No. 2005-35205-18653 and No. 2010-65205-20362) and start-up funds from the Pennsylvania State University to Liu, W-S.

\section{Author details}

${ }^{1}$ Department of Dairy and Animal Science, The Center for Reproductive Biology and Health (CRBH), College of Agricultural Sciences, The Pennsylvania State University, University Park, PA 16802, USA. ${ }^{2}$ The Integrative Biosciences Program, Bioinformatics and Genomics Option, The Huck Institute of Life Sciences, The Pennsylvania State University, University Park, PA 16802, USA. ${ }^{3}$ National Institute of Agrobiological Sciences, Tsukuba, Ibaraki, 305-0901, Japan. ${ }^{4}$ National Center for Genome Resources, Santa Fe, NM 87505, USA. ${ }^{5}$ Current address: Department of Pathology and Laboratory Medicine, School of Medicine, University of North Carolina-Chapel Hill, Chapel Hill, NC 27599, USA.

\section{Authors' contributions}

YY participated in the design of the study, carried out the cDNA selection, cloning and sequencing, gene structure and expression analyses, and drafted the manuscript. TCC performed the bioinformatics and phylogenetic analysis, Y chromosome sequence assembly, deep-sequencing analysis, and drafted the manuscript. HY carried out the ISH experiment. AKB and EFR performed the deep-sequencing of the selected CDNA and contig assembly. WSL conceived and designed the study, interpreted the results and revised the manuscript critically. All authors read and approved the final manuscript.

Received: 10 August 2010 Accepted: 7 January 2011

Published: 7 January 2011

\section{References}

1. Veyrunes F, Waters PD, Miethke P, Rens W, McMillan D, Alsop AE, Grützner F, Deakin JE, Whittington CM, Schatzkamer K, et al: Bird-like sex chromosomes of platypus imply recent origin of mammal sex chromosomes. Genome research 2008, 18(6):965-973.

2. Warren WC, Hillier LW, Marshall Graves JA, Birney E, Ponting CP, Grutzner F, Belov K, Miller W, Clarke L, Chinwalla AT, et al: Genome analysis of the platypus reveals unique signatures of evolution. Nature 2008, 453(7192):175-183.

3. Graves JA: Sex chromosome specialization and degeneration in mammals. Cell 2006, 124(5):901-914.

4. Skaletsky H, Kuroda-Kawaguchi T, Minx PJ, Cordum HS, Hillier L, Brown LG, Repping S, Pyntikova T, Ali J, Bieri T, et al: The male-specific region of the human $\mathrm{Y}$ chromosome is a mosaic of discrete sequence classes. Nature 2003, 423(6942):825-837.

5. Sinclair AH, Berta P, Palmer MS, Hawkins JR, Griffiths BL, Smith MJ, Foster JW, Frischauf AM, Lovell-Badge R, Goodfellow PN: A gene from the human sex-determining region encodes a protein with homology to a conserved DNA-binding motif. Nature 1990, 346(6281):240-244.

6. Berta P, Hawkins JR, Sinclair AH, Taylor A, Griffiths BL, Goodfellow PN, Fellous M: Genetic evidence equating SRY and the testis-determining factor. Nature 1990, 348(6300):448-450.

7. Ross MT, Grafham DV, Coffey AJ, Scherer S, McLay K, Muzny D, Platzer M, Howell GR, Burrows C, Bird CP, et al: The DNA sequence of the human X chromosome. Nature 2005, 434(7031):325-337.

8. Lahn BT, Page DC: Four evolutionary strata on the human $X$ chromosome. Science (New York, NY 1999, 286(5441):964-967.

9. Ohno S: Sex Chromosomes and sex-linked genes. Berlin:Springer-VerlagNew York; 1967.

10. Wilson MA, Makova KD: Evolution and survival on eutherian sex chromosomes. PLoS genetics 2009, 5(7):e1000568.

11. Graves JA: Evolution of the mammalian Y chromosome and sexdetermining genes. The Journal of experimental zoology 1998, 281(5):472-481.

12. Charlesworth B, Charlesworth D: The degeneration of $Y$ chromosomes. Philosophical transactions of the Royal Society of London 2000, 355(1403):1563-1572.
13. Roze D, Barton NH: The Hill-Robertson effect and the evolution of recombination. Genetics 2006, 173(3):1793-1811.

14. Pearks Wilkerson AJ, Raudsepp T, Graves T, Albracht D, Warren W, Chowdhary BP, Skow LC, Murphy WJ: Gene discovery and comparative analysis of $\mathrm{X}$-degenerate genes from the domestic cat $\mathrm{Y}$ chromosome. Genomics 2008, 92(5):329-338.

15. Lahn BT, Page DC: Functional coherence of the human $Y$ chromosome. Science (New York, NY 1997, 278(5338):675-680.

16. Hurst LD: Embryonic growth and the evolution of the mammalian $Y$ chromosome. I. The $\mathrm{Y}$ as an attractor for selfish growth factors. Heredity 1994, 73(Pt 3):223-232.

17. Marshall Graves JA: Human Y chromosome, sex determination, and spermatogenesis - a feminist view. Biology of reproduction 2000, 63(3):667-676.

18. Church DM, Goodstadt L, Hillier LW, Zody MC, Goldstein S, She X, Bult CJ, Agarwala R, Cherry JL, DiCuccio $M$, et al: Lineage-specific biology revealed by a finished genome assembly of the mouse. PLoS biology 2009, 7(5): e1000112.

19. Bhowmick BK, Satta Y, Takahata N: The origin and evolution of human ampliconic gene families and ampliconic structure. Genome research 2007, 17(4):441-450.

20. Murphy WJ, Pearks Wilkerson AJ, Raudsepp T, Agarwala R, Schaffer AA, Stanyon R, Chowdhary BP: Novel gene acquisition on carnivore $Y$ chromosomes. PLoS genetics 2006, 2(3):e43.

21. Hughes JF, Skaletsky H, Pyntikova T, Minx PJ, Graves T, Rozen S, Wilson RK, Page DC: Conservation of Y-linked genes during human evolution revealed by comparative sequencing in chimpanzee. Nature 2005 437(7055):100-103.

22. Lahn BT, Page DC: Retroposition of autosomal mRNA yielded testisspecific gene family on human Y chromosome. Nat Genet 1999, 21(4):429-433.

23. Kleiman SE, Yogev L, Hauser R, Botchan A, Bar-Shira Maymon B, Schreiber L, Paz G, Yavetz H: Members of the CDY family have different expression patterns: CDY1 transcripts have the best correlation with complete spermatogenesis. Human genetics 2003, 113(6):486-492.

24. Dorus S, Gilbert SL, Forster ML, Barndt RJ, Lahn BT: The CDY-related gene family: coordinated evolution in copy number, expression profile and protein sequence. Human molecular genetics 2003, 12(14):1643-1650.

25. Lahn BT, Tang ZL, Zhou J, Barndt RJ, Parvinen M, Allis CD, Page DC: Previously uncharacterized histone acetyltransferases implicated in mammalian spermatogenesis. Proceedings of the National Academy of Sciences of the United States of America 2002, 99(13):8707-8712.

26. Kleiman SE, Lagziel A, Yogev L, Botchan A, Paz G, Yavetz H: Expression of CDY1 may identify complete spermatogenesis. Fertility and sterility 2001, 75(1):166-173.

27. Slee R, Grimes B, Speed RM, Taggart M, Maguire SM, Ross A, McGill NI, Saunders PT, Cooke HJ: A human DAZ transgene confers partial rescue of the mouse Dazl null phenotype. Proceedings of the National Academy of Sciences of the United States of America 1999, 96(14):8040-8045.

28. Ruggiu M, Speed R, Taggart M, McKay SJ, Kilanowski F, Saunders P, Dorin J, Cooke HJ: The mouse Dazla gene encodes a cytoplasmic protein essential for gametogenesis. Nature 1997, 389(6646):73-77.

29. Houston DW, King ML: A critical role for Xdazl, a germ plasm-localized RNA, in the differentiation of primordial germ cells in Xenopus. Development (Cambridge, England) 2000, 127(3):447-456.

30. Eberhart CG, Maines JZ, Wasserman SA: Meiotic cell cycle requirement for a fly homologue of human Deleted in Azoospermia. Nature 1996, 381(6585):783-785

31. Yen PH: Putative biological functions of the DAZ family. International journal of andrology 2004, 27(3):125-129.

32. Kee $K$, Angeles VT, Flores M, Nguyen HN, Reijo Pera RA: Human DAZL, DAZ and BOULE genes modulate primordial germ-cell and haploid gamete formation. Nature 2009, 462(7270):222-225.

33. Liu W-S, Wang A, Uno Y, Galitz D, Beattie CW, Ponce de León FA: Genomic structure and transcript variants of the bovine DAZL gene. Cytogenet Genome Res 2007, 116(1-2):65-71.

34. Wang A, Yasue H, Li L, Takashima M, Ponce de León FA, Liu W-S: Molecular characterization of the bovine chromodomain Y-like genes. Animal genetics 2008, 39(3):207-216. 
35. Elsik CG, Tellam RL, Worley KC, Gibbs RA, Muzny DM, Weinstock GM Adelson DL, Eichler EE, Elnitski L, Guigo R, et al: The genome sequence of taurine cattle: a window to ruminant biology and evolution. Science (New York, NY 2009, 324(5926):522-528.

36. Ponce de León FA: Microdissected chromosome libraries for livestock species. Arch Zootec 1996, 45:165-174

37. Liu W-S, Ponce de León FA: Mapping of the Bovine Y Chromosome. Electronic Journal of Biology 2007, 3(1):8.

38. Liu W-S, Wang A, Yang Y, Chang T-C, Landrito E, Yasue H: Molecular characterization of the DDX3Y gene and its homologs in cattle. Cytogenetic and Genome Research 2009, 126(4):318-328

39. Liu W-S, Mariani P, Beattie CW, Alexander L, Ponce de León FA: A radiation hybrid map for the bovine $Y$ Chromosome. Mammalian Genome 2002, 13(6):320-326.

40. Liu W-S: Comparative Genomics of the Y Chromosome and Male Fertility. In Reproductive genomics in domestic animals. 1 edition. Edited by: Jiang Z, Ott TL. Ames, lowa: Wiley-Blackwell; 2010:129-146.

41. Liu W-S, Ponce de León FA: Assignment of SRY, ANT3, and CSF2RA to the bovine $\mathrm{Y}$ chromosome by FISH and $\mathrm{RH}$ mapping. Animal Biotechnology 2004, 15(2):103-109.

42. Del Mastro RG, Lovett M: Isolation of coding sequences from genomic regions using direct selection. Methods in molecular biology (Clifton, $\mathrm{NJ}$ 1997, 68:183-199.

43. Ponce de León FA, Ambady S, Hawkins GA, Kappes SM, Bishop MD, Robl JM, Beattie CW: Development of a bovine X chromosome linkage group and painting probes to assess cattle, sheep, and goat $X$ chromosome segment homologies. Proceedings of the National Academy of Sciences of the United States of America 1996, 93(8):3450-3454.

44. Kapustin Y, Souvorov A, Tatusova T, Lipman D: Splign: algorithms for computing spliced alignments with identification of paralogs. Biology direct 2008, 3:20

45. Thomsen PD, Jorgensen CB: Distribution of two conserved, male-enriched repeat families on the Bos taurus Y chromosome. Mamm Genome 1994, 5(3):171-173.

46. Kumar S, Hedges SB: A molecular timescale for vertebrate evolution. Nature 1998, 392(6679):917-920.

47. Birtle Z, Goodstadt L, Ponting C: Duplication and positive selection among hominin-specific PRAME genes. BMC genomics 2005, 6:120

48. Saxena R, Brown LG, Hawkins T, Alagappan RK, Skaletsky H, Reeve MP, Reijo R, Rozen S, Dinulos MB, Disteche CM, et al: The DAZ gene cluster on the human $Y$ chromosome arose from an autosomal gene that was transposed, repeatedly amplified and pruned. Nat Genet 1996, 14(3):292-299.

49. Lahn BT, Page DC: Retroposition of autosomal mRNA yielded testisspecific gene family on human Y chromosome. Nature Genetics 1999, 21(4):429-433

50. Linardopoulou EV, Williams EM, Fan Y, Friedman C, Young JM, Trask BJ: Human subtelomeres are hot spots of interchromosomal recombination and segmental duplication. Nature 2005, 437(7055):94-100

51. Nei M, Gu X, Sitnikova T: Evolution by the birth-and-death process in multigene families of the vertebrate immune system. Proceedings of the National Academy of Sciences of the United States of America 1997 94(15):7799-7806.

52. Roldan Gomendio: The Y chromosome as a battle ground for sexual selection. Trends in ecology \& evolution (Personal edition) 1999, 14(2):58-62

53. Rozen S, Skaletsky H, Marszalek JD, Minx PJ, Cordum HS, Waterston RH, Wilson RK, Page DC: Abundant gene conversion between arms of palindromes in human and ape Y chromosomes. Nature 2003, 423(6942):873-876.

54. Nickkholgh B, Noordam MJ, Hovingh SE, van Pelt AM, van der Veen F, Repping S: Y chromosome TSPY copy numbers and semen quality. Fertil Steril 2010, 94(5):1744-1747.

55. Jakubiczka S, Schnieders F, Schmidtke J: A bovine homologue of the human TSPY gene. Genomics 1993, 17(3):732-735.

56. Verkaar EL, Zijlstra C, van 't Veld EM, Boutaga K, van Boxtel DC, Lenstra JA: Organization and concerted evolution of the ampliconic Y-chromosomal TSPY genes from cattle. Genomics 2004, 84(3):468-474

57. Hamilton CK, Favetta LA, Di Meo GP, Floriot S, Perucatti A, Peippo J, Kantanen J, Eggen A, lannuzzi L, King WA: Copy number variation of testis-specific protein, Y-encoded (TSPY) in 14 different breeds of cattle (Bos taurus). Sex Dev 2009, 3(4):205-213.
58. Vodicka R, Vrtel R, Dusek L, Singh AR, Krizova K, Svacinova V, Horinova V, Dostal J, Oborna I, Brezinova J, et al: TSPY gene copy number as a potential new risk factor for male infertility. Reprod Biomed Online 2007, 14(5):579-587.

59. Giachini C, Nuti F, Turner DJ, Laface I, Xue Y, Daguin F, Forti G, TylerSmith C, Krausz C: TSPY1 copy number variation influences spermatogenesis and shows differences among $Y$ lineages. J Clin Endocrinol Metab 2009, 94(10):4016-4022.

60. Laity $\mathrm{JH}$, Lee $\mathrm{BM}$, Wright PE: Zinc finger proteins: new insights into structural and functional diversity. Current opinion in structural biology 2001, 11(1):39-46

61. Modolell J, Bender W, Meselson M: Drosophila melanogaster mutations suppressible by the suppressor of Hairy-wing are insertions of a 7.3kilobase mobile element. Proceedings of the National Academy of Sciences of the United States of America 1983, 80(6):1678-1682.

62. Adryan B, Woerfel G, Birch-Machin I, Gao S, Quick M, Meadows L, Russell S, White R: Genomic mapping of Suppressor of Hairy-wing binding sites in Drosophila. Genome Biol 2007, 8(8):R167.

63. Gunn SR, Bolla AR, Barron LL, Gorre ME, Mohammed MS, Bahler DW Mellink CHM, van Oers MHJ, Keating MJ, Ferrajoli A, et al: Array CGH analysis of chronic lymphocytic leukemia reveals frequent cryptic monoallelic and biallelic deletions of chromosome 22q11 that include the PRAME gene. Leukemia research 2009, 33(9):1276-1281.

64. Isahakia MA: Characterization of baboon testicular antigens using monoclonal anti-sperm antibodies. Biol Reprod 1988, 39(4):889-899.

65. Conway SJ, Mahadevaiah SK, Darling SM, Capel B, Rattigan AM, Burgoyne PS: Y353/B: a candidate multiple-copy spermiogenesis gene on the mouse $Y$ chromosome. Mamm Genome 1994, 5(4):203-210.

66. Toure A, Grigoriev V, Mahadevaiah SK, Rattigan A, Ojarikre OA, Burgoyne PS: A protein encoded by a member of the multicopy Ssty gene family located on the long arm of the mouse $Y$ chromosome is expressed during sperm development. Genomics 2004, 83(1):140-147.

67. Lee T-L, Pang AL-Y, Rennert OM, Chan W-Y: Genomic landscape of developing male germ cells. Birth Defects Research Part C, Embryo Today: Reviews 2009, 87(1):43-63.

68. Liu W-S, Wang A, Yang Y, Chang T-C, Landrito E, Yasue H: Molecular Characterization of the DDX3Y Gene and Its Homologs in Cattle. Cytogenetic and Genome Res 2009, 126(4):318-328.

69. Sambrook J, Russell DW: Molecular Cloning. Cold Spring Harbor Laboratory Press: Third 20011.

70. Liu W-S, Mariani P, Beattie CW, Alexander LJ, Ponce De León FA: A radiation hybrid map for the bovine $Y$ Chromosome. Mamm Genome 2002, 13(6):320-326.

71. Kiuchi S, Yamada T, Kiyokawa N, Saito T, Fujimoto J, Yasue H: Genomic structure of swine taste receptor family 1 member 3, TAS1R3, and its expression in tissues. Cytogenetic and genome research 2006, 115(1):51-61

72. Ohtsuki T, Furuya S, Yamada T, Nomura S, Hata J, Yabe Y, Hosoda Y: Gene expression of noncollagenous bone matrix proteins in the limb joints and intervertebral disks of the twy mouse. Calcified tissue international 1998, 63(2):167-172

73. Wu TD, Nacu S: Fast and SNP-tolerant detection of complex variants and splicing in short reads. In Bioinformatics. Volume 26. Oxford, England; (7):873-881.

74. Miller NA, Kingsmore SF, Farmer A, Langley RJ, Mudge J, Crow JA Gonzalez AJ, Schilkey FD, Kim RJ, van Velkinburgh J, et al: Management of High-Throughput DNA Sequencing Projects: Alpheus. Journal of computer science and systems biology 2008, 1:132.

75. Florea L, Hartzell G, Zhang Z, Rubin GM, Miller W: A computer program for aligning a cDNA sequence with a genomic DNA sequence. Genome research 1998, 8(9):967-974.

76. Rice P, Longden I, Bleasby A: EMBOSS: the European Molecular Biology Open Software Suite. Trends in Genetics: TIG 2000, 16(6):276-277.

77. Tamura K, Dudley J, Nei M, Kumar S: MEGA4: Molecular Evolutionary Genetics Analysis (MEGA) software version 4.0. Molecular biology and evolution 2007, 24(8):1596-1599.

78. Nei M, Gojobori T: Simple methods for estimating the numbers of synonymous and nonsynonymous nucleotide substitutions. Molecular biology and evolution 1986, 3(5):418-426.

79. Tamura K, Nei M, Kumar S: Prospects for inferring very large phylogenies by using the neighbor-joining method. Proc Natl Acad Sci USA 2004, 101(30):11030-11035.

80. Smit AFAHR, Green P: RepeatMasker Open-3.0. 1996 
81. Krumsiek J, Arnold R, Rattei T: Gepard: a rapid and sensitive tool for creating dotplots on genome scale. In Bioinformatics. Volume 23. Oxford, England; 2007:(8):1026-1028.

82. Altschul SF, Gish W, Miller W, Myers EW, Lipman DJ: Basic local alignment search tool. Journal of Molecular Biology 1990, 215(3):403-410

83. Felsenstein J: Confidence Limits on Phylogenies: An Approach Using the Bootstrap. Evolution 1985, 39(4):791-783.

doi:10.1186/1471-2164-12-13

Cite this article as: Yang et al:: ZNF280BY and ZNF280AY: autosome derived Y-chromosome gene families in Bovidae. BMC Genomics 2011 12:13.

Submit your next manuscript to BioMed Central and take full advantage of:

- Convenient online submission

- Thorough peer review

- No space constraints or color figure charges

- Immediate publication on acceptance

- Inclusion in PubMed, CAS, Scopus and Google Scholar

- Research which is freely available for redistribution 